\title{
PENGARUH BRAND EXPERIENCE, BRAND IMAGE-CONGRUENCE, BRAND AFFECT DAN BRAND TRUST TERHADAP REPURCHASE INTENTION PADA PRODUK FASHION BERRYBENKA SECARA ONLINE DI JAKARTA
}

\author{
WIBISONO SOEDIONON \\ KLEMENS WEDANAJI PRASASTYO \\ MARIA ADELINE \\ Trisakti School of Management, Jl. Kyai Tapa No 20 Jakarta, Indonesia \\ wibisono@stietrisakti.ac.id, klemens@stietrisakti.ac.id
}

\begin{abstract}
The purpose of this study is to know how the influence of Brand Experience, Brand Image-Congruence, Brand Affect and Brand Trust to Repurchase Intention product online apparel Berrybenka at Jakarta. The research design used in descriptive research and causality research. The sampling used in this research is nonprobability sampling by purposive sampling methods and will require 107 respondents. The respondents must be using product online apparel Berrybenka. The method for analyzing data uses structural equation modeling (SEM), which uses the partial least square analysis program SmartPLS 3.0. The result showed that brand experience have an impact to brand affect. Brand image-congruence have an impact to brand affect. Brand experience have an impact to brand trust. Brand image-congruence have an impact to brand trust. Brand affect have an impact to brand trust. Brand experience have an impact to repurchase intention. Brand image-congruence have an impact to repurchase intention. Brand trust have an impact to repurchase intention.
\end{abstract}

Keywords: Brand experience, brand image-congruence, brand affect, brand trust, repurchase intention

\begin{abstract}
Abstrak: Tujuan penelitian adalah untuk mengidentifikasi dan menganalisis Pengaruh Brand Experience, Brand Image-Congruence, Brand Affect dan Brand Trust terhadap Repurchase Intention pada Produk Pakaian Berrybenka Secara Online. Teknik sampling yang digunakan pada penelitian ini adalah nonprobability sampling dengan metode purposive sampling dan akan membutuhkan 107 responden. Responden merupakan konsumen yang menggunakan dan memakai produk pakaian Berrybenka secara online. Metode untuk menganalisis data menggunakan model persamaan struktural (SEM), yang menggunakan program analisis partial least square yaitu SmartPLS 3.0. Hasil dari penelitian ini menunjukkan terdapat pengaruh brand experience terhadap brand affect. Terdapat pengaruh brand image-congruence terhadap brand affect. Tidak terdapat pengaruh brand experience terhadap brand trust. Terdapat pengaruh brand image-congruence terhadap brand trust. Terdapat pengaruh brand affect terhadap brand trust. Tidak terdapat pengaruh brand experience terhadap repurchase intention. Terdapat pengaruh brand image-congruence terhadap repurchase intention. Terdapat pengaruh brand trust terhadap repurchase intention.
\end{abstract}

Kata kunci: Brand experience, brand image-congruence, brand affect, brand trust, repurchase intention 


\section{PENDAHULUAN}

Teknologi semakin pesat perkembangannya pada era modern sekarang ini. Salah satu teknologi yang berkembang pesat sekarang ini adalah internet. Berperan menjadi sebuah alat penunjang bagi sebagian aktivitas kehidupan manusia sehari-hari. Internet sebagai penyedia informasi dan penyebaran informasi yang cepat, efisien dan mudah di akses dimanapun. Dampak yang diberikan oleh berkembangnya internet mempengaruhi berbagai aspek, salah satunya adalah aspek ekonomi.Tingginya pengaruh internet membantu mempermudah kegiatan jual beli yang merupakan bagian dari kegiatan ekonomi. Peluang usaha baru yang dapat dimanfaatkan penjual maupun pembeli dengan membuka tokonya secara online secara gratis. Fasilitas yang sering digunakan untuk berbelanja secara online disebut dengan e-commerce.

Menurut Kotler dan Keller $(2015,536)$ e-commerce sarana bertransaksi, memfasilitasi penjualanan dan layanan secara online. Perdangangan secara online atau yang disebut dengan e-commerce ini memberikan beberapa manfaat seperti tersedianya berbagai pilihan kategori yang dibutuhkan dan menemukan produk yang sulit ditemukan pada toko offline. Mendorong tren dalam berbelanja secara online di Indonesia, konsumen tidak lagi datang ke toko offline untuk memilih dan membeli, hanya dengan menggunakan smartphone atau komputer sebagai alat bantu yang dapat mengakses internet. Tersedia 24 jam sehingga konsumen dapat mengakses kapanpun dan dimanapun serta mengetahui berbagai promo menarik tanpa mengenal waktu dan terkadang harga yang diberikan lebih murah dibandingkan toko-toko offline seperti biasanya. Menurut Keegan dan Green (2017, 394-395) menjadi tiga kategori dasar yaitu Business to Business, Business to Consumer dan Peer to Peer.

Banyak pemasar melirik memasarkan produk melalui internet yang dapat memperkenalkan nama suatu usaha ke publik dan mendorong konsumen mencari informasi lebih lanjut tentang suatu usaha tersebut. Menurut Kotler and Keller (2015, 652) menyatakan online marketing memberikan kesempatan bagi pemasar secara lebih luas berinteraksi dan memasarkan produk atau jasa melalui situs web di internet.

E-commerce menyediakan berbagai kategori dari kebutuhan sehari - hari hingga yang sulit ditemukan pada toko offline. Survey yang dilakukan oleh snapcart menujukkan bahwa kategori clothing atau fashion menjadi peringkat pertama yang diminati untuk dibeli, data pada tahun 2018 ini mencatat dengan persentase sebesar $48 \%$ penjualan di e-commerce.

Berrybenka merupakan e-commerce fashion yang memberikan dua metode dalam melakukan pembayaran dengan transfer bank atau dengan COD (cash on delivery). Persaingan online antar industri fashion dapat dilihat melalui Top Brand Index.

Berdasarkan data Top Brand Index memperlihatkan perubahaan fluktuatif Berrybenka dalam 4 tahun terakhir. Tahun 2015 Berrybenka memiliki persentase 3,3\% yang menurun dan sempat menghilang pada tahun 2016. Persentase pada tahun 2017 naik dengan cukup baik sebesar $6,4 \%$ namun turun kembali menjadi 4,9\%. Dilihat dari data tersebut Berrybenka dapat dikalahkan oleh Lazada yang tidak memiliki fokus pada produk apparel (baju) dan kembali dikalahkan pada tahun 2018 oleh Shopee yang tidak juga berfokus terhadap produk fashion. Melihat Berrybenka bukan pendatang baru dalam industri online fashion, sehingga Berrybenka harus meningkatkan daya saing agar 
penjualan Berrybenka dapat menempati kembali posisi tiga teratas.

Salah satu cara meningkatkan daya saing Berrybenka dengan meningkatkan repurchase intention pelanggan, karena menurut Setyorini dan Nugraha $(2016,5)$ mengatakan bahwa dengan tingginya minat pembelian ulang perusahan dapat berkompetisi dengan pesaingnya dikarenakan adanya niat konsumen untuk membeli produk atau layanan yang ditawarkan oleh vendor atau toko online setelah mendapatkan pengalaman positif terkait penggunaan produk atau layanan tersebut. Penelitian yang dilakukan Aslam et al (2018) menyatakan hasilnya bahwa brand experience, brand image-congruence, brand affect dan brand trust merupakan faktorfaktor yang dapat mempengaruhi repurchase intention.

Faktor pertama yang mempengaruhi adalah brand experience, menurut Alloza (2008, 373) didefinisikan persepsi konsumen pada setiap momen hubungan yang mereka miliki dengan merek secara tidak langsung maupun langsung, pemasaran yang dilakukan dengan iklan hubungan tidak langsung serta merasakan sendiri pengalaman dengan membeli dan menggunakannya secara pribadi sebagai hubungan atas pengalaman langsung. Pengalaman yang positif memberikan peluang terciptanya respon emosional yang positif, hal ini dikarenakan merek tersebut memenuhi pengalaman yang diinginkan, dipikirkan, dan dirasakan konsumen. Respon positif didasarkan oleh pengalaman ini didukung oleh pendapat Peter and Olson $(2009,5)$ bahwa pikiran dan perasaan yang dialami oleh konsumen didasarkan pengalaman untuk melakukan proses konsumsi. Kepercayaan akan produk dalam berbelanja online sudah menjadi hal penting yang harus diperhatikan oleh merek karena pengalaman menjadi evaluasi dasar suatu konsumen dalam mengambil keputusan mempercayai produk atau tidak, hal ini didukung oleh Ramaseshan and Stein (2014, 668) mengatakan pengalaman berfungsi sumber input pribadi dan menumbuhkan rasa percaya pada konsumen. Respon emosional yang didasarkan oleh pengalaman sehingga konsumen percaya bahwa keinginan dan kebutuhan konsumen dapat terpenuhi mendorong konsumen membeli kembali pada tempat yang sama, pernyataan ini didukung oleh Foster $(2017,71)$ menyatakan bahwa konsumen merasa puas atas kegiatan pembelian secara online yang pernah dilakukan, menjadi pengalaman positif yang menjadi dasar konsumen pergi kembali ke toko yang sama.

Faktor kedua yang mempengaruhi adalah brand image-congruence, menurut Wu and $Y e(2016,537)$ adalah persepsi dan tingkat kesesuaian antara citra dan kepribadian yang diberikan merek dan citra yang ditunjukkan oleh konsumen sendiri. Merek harus dapat memposisikan diri sebagai manusia yang mengandung citra tertentu yang dapat berada di benak konsumen. Seorang konsumen yang merasakan tingkat kesesuaian cukup besar antara citra diri dengan citra yang ditampilkan oleh merek menganggap positif merek tersebut, hal ini didukung oleh Rhee dan Johnson $(2012,2)$ berpendapat bagaimana konsumen menggunakan produk merek yang memiliki hubungan dengan konsep diri konsumen. Kesesuaian memiliki peran penting dalam membangun rasa percaya, bahwa merek dapat memenuhi kebutuhan yang konsumen inginkan dan tidak mendapatkannya di merek lain. Menurut Coulter dan Coulter $(2002,38)$ menyatakan kesesuaian antara konsumen dan merek dalam menggambarkan citra diri menciptakan rasa percaya, hal ini mendukung bahwa merek yang sesuai antara konsumen dan merek secara postif memotivasi konsumen percaya terhadap merek. Konsumen yang memiliki rasa kesamaan dengan merek dan 
tingkat kepercayaan yang sudah tinggi atas pengalaman yang sudah pernah dialami dan diingat memiliki peluang untuk membeli produk secara terus menerus di merek yang sama. Menurut Chen-Yu et al $(2016,41)$ mendukung adanya keterkaitan antara citra merek dengan pembelian kembali berpendapat citra yang dibangun merek membantu konsumen berbelanja online fashion terhubung secara emosional, mempercayai produk sehingga dorongan membeli kembali produk pada merek yang sama dapat terjadi.

Faktor ketiga yang mempengaruhi adalah brand affect, Kumar dan Kesharwani (2016, 5 ) adalah berupa suatu perasaan negatif atau positif yang timbul dari interaksi dengan merek berupa nama merek, logo maupun slogan. Konsumen yang memiliki perasaan positif dan menyukai produk fashion merek tertentu didasarkan oleh interaksi dengan merek dan kesesuain dengan konsep diri memberikan respon motivasi untuk konsumen mempelajari dan mendapatkan informasi yang lebih banyak sehingga meningkatkan kepercayaan akan merek, hal ini didukung oleh Lau dan Lee $(1999,310)$ berpendapat kepercayaan konsumen terhadap merek sebagai respon emosional untuk mempelajari lebih lanjut tentang merek. Faktor terakhir yang mempengaruhi adalah brand trust, menjelaskan ketika konsumen percaya pada merek, didasari konsumen harus melihat merek sebagai hal positif dalam layanan maupun kualitasnya (Trisnawati et al 2013). Mempercayai suatu merek adalah hal terpenting yang dibutuhkan oleh konsumen untuk mengurangi resiko dan kecewa sehingga membeli produk online fashion pada merek-merek yang sudah dipercayai. Konsumen yang sudah merasakan kepercayaan terhadap suatu merek akan membuat merek loyal sehingga berpeluang konsumen memiliki niat dalam membeli kembali produk fashion pada merek yang sama. Hal ini didukung oleh Lin and Lee (2012, 312) berpendapat jika sudah mempercayai suatu online fashion, konsumen cenderung melakukan pembelian berulang. Berdasarkan latar belakang diatas, penulis merasa tertarik untuk melakukan penelitian dengan mengangkat judul "Pengaruh Brand Experience, Brand ImageCongruence, Brand Affect dan Brand Trust terhadap Repurchase Intention pada Produk Fashion Berrybenka Secara Online".

\section{Brand Experience}

Pengalaman seseorang setelah menggunakan merek yang menghasilkan respon perasaan dan perilaku seseorang dengan cara membicarakan dan mencari informasi yang berkaitan dengan merek yang menggunakan (Brakus 2009, ChenYu 2016, 32 Kusuma 2014,2).

Brand Image-Congruece Brand Image-Congruence merupakan evaluasi yang dilakukan oleh konsumen didasarkan kecocokan antara konsep diri konsumen dengan konsep diri merek (Keegan 2016, 329, Auzolt 2015,321, Sirgy 2008, 1092).

Brand Affect

Merek dapat mempengaruhi potensi mendapatkan respon emosional sebagai akibat pengalaman konsumen terhadap penggunaan produk dievaluasi (Kabadayi dan Alan 2012, 81, Chauduri dan Holbrook 2001,82, ChenYu 2016, 82).

Brand Trust

Kepercayaan konsumen terhadap merek menjadi dasar merek dapat sukses dengan pengembangan penglolaan hunungan jangka panjang (Fianto 2014, 63, Kim and Kim 2009, 127, Srivasta 2016,1). Repurchase Intention

Perilaku seorang konsumen berkeinginan membeli kembali produk dengan merek yang sama yang ditimbulkan dari sikap positif dari hasil evaluasi atas 
kesesuaian dengan harapan yang diinginkan terhadap merek berdasarkan pengalaman dengan merek tersebut (Aslam 2018, 90, Suryana dan Dasuki 2013, 195, Fang 2011 , 484).

\section{Brand Experience terhadap Brand Affect}

Pikiran dan perasaan yang dialami oleh konsumen didasarkan pengalaman untuk melakukan proses konsumsi (Peter and Olson 2009, 5)

$\mathrm{H}_{1}$ Terdapat pengaruh brand experience terhadap brand affect

\section{Brand Image-Congruence terhadap Brand Affect}

Bagaimana konsumen menggunakan produk merek yang memiliki hubungan dengan konsep diri konsumen (Rhee dan Johnson 2012, 2)

$\mathrm{H}_{2}$ Terdapat pengaruh brand imagecongruence terhadap brand affect

\section{Brand Experience terhadap Brand Trust}

Pengalaman berfungsi sumber input pribadi dan menumbuhkan rasa percaya pada konsumen (Ramaseshan and Stein 2014, 668)

$\mathrm{H}_{3}$ Terdapat pengaruh brand experience terhadap brand trust

\section{Brand Image-Congruence terhadap Brand Trust}

Kesesuaian antara konsumen dan merek dalam menggambarkan citra diri menciptakan rasa percaya, hal ini mendukung bahwa merek yang sesuai antara konsumen dan merek secara postif memotivasi konsumen percaya terhadap merek (Coulter dan Coulter 2002, 38)

$\mathrm{H}_{4}$ Terdapat pengaruh brand imagecongruence terhadap brand trust

\section{Brand Affect terhadap Brand Trust}

Kepercayaan konsumen terhadap merek sebagai respon emosional untuk mempelajari lebih lanjut tentang merek (Lau dan Lee 1999, 310)

$\mathrm{H}_{5}$ Terdapat pengaruh brand affect terhadap brand trust

\section{Brand Experience terhadap Repurchase Intention}

Konsumen merasa puas atas kegiatan pembelian secara online yang pernah dilakukan, menjadi pengalaman positif yang menjadi dasar konsumen pergi kembali ke toko yang sama (Foster 2017, 71) $\mathrm{H}_{6}$ Terdapat pengaruh brand experience terhadap repurchase intention

\section{Brand Image-Congruence terhadap Repurchase Intention}

Citra yang dibangun merek membantu konsumen berbelanja online apparel terhubung secara emosional, mempercayai produk sehingga dorongan membeli kembali produk pada merek yang sama dapat terjadi ChenYu $(2016,41)$

$\mathrm{H}_{7}$ Terdapat pengaruh brand imagecongruence terhadap repurchase intention

\section{Brand Trust terhadap Repurchase Intention}

Jika sudah mempercayai suatu online apparel, konsumen cenderung melakukan pembelian berulang (Lin and Lee 2012, 312) $\mathrm{H}_{8}$ Terdapat pengaruh brand trust terhadap repurchase intention.

\section{METODE PENELITIAN}

Penelitian ini dilakukan dengan tujuan untuk mengetahui apakah brand experience, brand image-congruence, brand affect, dan brand trust mempengaruhi repurchase intention produk pakaian Berrybenka secara online. Rancangan penelitian adalah penelitian deskriptif dan hubungan kausalitas. Objek dalam penelitian ini adalah produk pakaian Berrybenka secara online. Metode pegumpulan data yang digunakan dalam penelitian ini 
kuesioner. Responden dalam penelitian ini merupakan konsumen yang menggunakan dan memakai produk pakaian.Berrybenka secara online.

Jumlah sample dalam penelitian ini sebanyak 107 responden. Variabel penelitian terdiri dari variabel.dependen yaitu variabel brand experience dan brand image-congruence, variael independen terdiri dari brand affect dan brand trust dan variabel independen yaitu repurchase intention. Semua variabel diukur dengan menggunakan skala likert, menurut.Sugiyono $(2014,132)$ skala likert digunakan untuk mengukur sikap, pendapat, dan perseps seseorang atau sekelompok orang tentang fenomena sosial yang sedang terjadi. Responden menjawab pertanyaan dengan memilih salah satu jawaban dari $1=$ Sangat Tidak Setuju, 2=Tidak Setuju, 3=Cukup Setuju, 4=Setuju, 5=Sangat Setuju.

\section{HASIL}

Berdasarkan hasil kuesioner yang disebarkan, dapat disimpulkan responden adalah sebagai berikut :

Tabel 1 Karakteristik Responden

\begin{tabular}{lll}
\hline Keterangan & & Jumlah \\
\hline Lama Penggunaan & $\leq 1$ tahun & 52 \\
& $2-3$ tahun & 38 \\
Frekuensi Belanja & $\geq 3$ tahun & 17 \\
Jenis Kelamin & $2-4$ kali & 70 \\
Usia & $\geq 5$ kali & 37 \\
& Laki-laki & 38 \\
& Perempuan & 69 \\
& $18-20$ tahun & 10 \\
Pendidikan & $21-23$ tahun & 63 \\
& $24-26$ tahun & 17 \\
Pekerjaan & $27-29$ tahun & 9 \\
& $\geq 30$ tahun & 8 \\
& SMA & 49 \\
& Diploma & 9 \\
& Sarjana & 49 \\
Mahasiswa/Pelajar & 24 \\
Kuliah dan Bekerja & 21 \\
Wiraswasta & 13 \\
Domisili & Pegawai Negri/Swasta & 42 \\
& lbu Rumah Tangga & 7 \\
Jakarta Barat & 51 \\
& Jakarta Utara & 16 \\
Jakarta Selatan & 13 \\
Jakarta Timur & 6 \\
& Jakarta Pusat & 21 \\
\hline
\end{tabular}

Berdasarkan kuesioner yang telah dikumpulkan menghasilkan statistik deskriptif sebagai berikut: 
Tabel 2 Descriptive Analysis of Variables Measured

\begin{tabular}{lll}
\hline Variabel & Mean & Srandard Error \\
\hline Brand Experience & 15,59 & 0,220 \\
Brand Image-Congruence & 18,58 & 0,292 \\
Brand Affect & 19,79 & 0,257 \\
Brand Trust & 15,36 & 0,212 \\
Rupurchase Intention & 15,60 & 0,229 \\
\hline
\end{tabular}

Tabel 3 Convergent Validity dan Composite Reliability

\begin{tabular}{llllll}
\hline Variabel & Items & Loading & AVE & $\begin{array}{l}\text { Composite } \\
\text { Reliability }\end{array}$ & $\begin{array}{l}\text { Cronbach } \\
\text { Alpha }\end{array}$ \\
\hline \multirow{3}{*}{ Brand } & BE1 & 0,863 & & & \\
Experience & BE2 & 0,868 & 0,624 & 0,868 & 0,798 \\
& BE3 & 0,739 & & & \\
& BE4 & 0,672 & & & \\
& BIC1 & 0,815 & & & \\
Brand Image- & BIC2 & 0,791 & & 0,858 \\
Congruence & BIC3 & 0,755 & 0,638 & 0,898 & \\
& BIC4 & 0,852 & & & \\
& BIC5 & 0,777 & & & \\
& BA1 & 0,758 & & & \\
Brand Affect & BA2 & 0,701 & & & \\
& BA3 & 0,834 & 0,593 & 0,879 & 0,827 \\
& BA4 & 0,766 & & & \\
& BA5 & 0,784 & & & \\
Brand Trust & BT1 & 0,814 & & & \\
& BT2 & 0,775 & 0,718 & \\
& BT3 & 0,644 & 0,542 & 0,824 & \\
Rupurchase & BT4 & 0,700 & & & \\
Intention & RP1 & 0,853 & & & \\
& RPI2 & 0,800 & \multirow{2}{*}{0,600} & 0,856 & 0,780 \\
& RP13 & 0,714 & & & \\
\hline
\end{tabular}


Tabel 4 Uji t

\begin{tabular}{|c|c|c|c|c|c|c|c|}
\hline & Hyphotesis & $\begin{array}{l}\text { Original } \\
\text { Sample } \\
\text { (0) }\end{array}$ & $\begin{array}{l}\text { Sampl } \\
\text { e } \\
\text { Mean } \\
\text { (M) }\end{array}$ & $\begin{array}{l}\text { Standard } \\
\text { Deviation } \\
\text { (STDEV) }\end{array}$ & $\begin{array}{l}\text { T } \\
\text { Statistics } \\
(\mid O / S T D E \\
V \mid)\end{array}$ & $\begin{array}{l}P \\
\text { Value } \\
s\end{array}$ & Supported \\
\hline $\mathrm{H} 1$ & $\mathrm{BE}>\mathrm{BA}$ & 0,509 & 0,519 & 0,070 & 7,306 & 0,000 & YES \\
\hline $\mathrm{H} 2$ & $\mathrm{BIC}>\mathrm{BA}$ & 0,348 & 0,345 & 0,070 & 4,962 & 0,000 & YES \\
\hline H3 & $\mathrm{BE}->\mathrm{BT}$ & 0,010 & 0,014 & 0,134 & 0,076 & 0,940 & NO \\
\hline H4 & $\mathrm{BIC}>\mathrm{BT}$ & 0,400 & 0,398 & 0,105 & 3,795 & 0,000 & YES \\
\hline H5 & $\mathrm{BA}>\mathrm{BT}$ & 0,335 & 0,339 & 0,150 & 2,235 & 0,026 & YES \\
\hline $\mathrm{H} 6$ & $\mathrm{BE}$-> RPI & 0,159 & 0,175 & 0,090 & 1,757 & 0,080 & NO \\
\hline $\mathrm{H} 7$ & $\mathrm{BIC}>\mathrm{RPI}$ & 0,288 & 0,273 & 0,097 & 2,973 & 0,003 & YES \\
\hline $\mathrm{H} 8$ & $\mathrm{BT}$-> RPI & 0,465 & 0,467 & 0,090 & 5,184 & 0,000 & YES \\
\hline
\end{tabular}

Hasil Hipotesis 1, bahwa diketahui pengaruh brand experience (BE) terhadap brand affect (BA) adalah signifikan, sebab nilai tstatistik lebih besar dari nilai t-tabel yaitu sebesar $7,306>1,96$. Sedangkan nilai original sampel estimate positif sebsar 0,509 menandakan bahwa pengaruh yang positif artinya $\mathrm{H}_{1}$ diterima. Kesimpulannya bahwa terdapat pengaruh brand experience terhadap brand affect.

Hasil hipotesis 2, bahwa diketahui pengaruh brand image-congruence (BIC) terhadap brand affect (BA) adalah signifikan, sebab nilai t-statistik lebih besar dari nilai t-tabel yaitu sebesar $4,962>1,96$. Sedangkan nilai original sampel estimate positif sebsar 0,348 menandakan bahwa pengaruh yang artinya $\mathrm{H}_{2}$ diterima. Kesimpulannya bahwa terdapat pengaruh brand image-congruence terhadap brand affect.

Hasil hipotesis 3, bahwa diketahui pengaruh brand experience (BE) terhadap brand trust (BT) adalah tidak signifikan, sebab nilai t-statistik lebih kecil dari nilai t-tabel yaitu sebesar $0,076>1,96$. Sedangkan nilai original sampel estimate positif sebsar 0,010 menandakan bahwa pengaruh yang artinya $\mathrm{H}_{3}$ ditolak. Kesimpulannya bahwa tidak terdapat pengaruh brand experience terhadap brand trust.
Hasil hipotesis 4, bahwa diketahui pengaruh brand image-congruence (BIC) terhadap bran trust (BT) adalah signifikan, sebab nilai t-statistik lebih besar dari nilai t-tabel yaitu sebesar $3,795>1,96$. Sedangkan nilai original sampel estimate positif sebsar 0,400 menandakan bahwa pengaruh yang artinya $\mathrm{H}_{4}$ diterima. Kesimpulannya bahwa terdapat pengaruh brand image-congruence terhadap brand trust.

Hasil hipotesis 5, bahwa diketahui pengaruh brand affect (BA) terhadap brand trust (BT) adalah signifikan , sebab nilai t-statistik lebih besar dari nilai t-tabel yaitu sebesar 2,235 $>1,96$. Sedangkan nilai original sampel estimate positif sebsar 0,335 menandakan bahwa pengaruh yang artinya $\mathrm{H}_{5}$ diterima. Kesimpulannya bahwa terdapat pengaruh brand trust terhadap brand affect.

Hasil hipotesis 6, bahwa diketahui pengaruh brand experience (BE) terhadap repurchase intention (RPI) adalah tidak signifikan, sebab nilai t-statistik lebih kecil dari nilai t-tabel yaitu sebesar 1,757 $<1,96$. Sedangkan nilai original sampel estimate positif sebsar 0,159 menandakan bahwa pengaruh yang artinya $\mathrm{H}_{6}$ ditolak. Kesimpulannya bahwa tidak terdapat pengaruh brand experience terhadap repurchase intention. 
Hasil hipotesis 7, bahwa diketahui pengaruh brand image-congruence (BIC) terhadap repurchase intention (RPI) adalah signifikan , sebab nilai t-statistik lebih besar dari nilai t-tabel yaitu sebesar $2,973>1,96$. Sedangkan nilai original sampel estimate positif sebsar 0,288 menandakan bahwa pengaruh yang artinya $\mathrm{H}_{7}$ diterima. Kesimpulannya bahwa terdapat pengaruh brand image-congruence terhadap repurchase intention.

Hasil hipotesis 8, bahwa diketahui pengaruh brand trust (BT) terhadap repurchase intention (RPI) adalah signifikan, sebab nilai tstatistik lebih besar dari nilai t-tabel yaitu sebesar $5,184>1,96$. Sedangkan nilai original sampel estimate positif sebsar 0,465 menandakan bahwa pengaruh yang artinya $\mathrm{H}_{8}$ diterima. Kesimpulannya bahwa terdapat pengaruh brand trust terhadap repurchase intention.

\section{PENUTUP}

Berdasarkan penelitian yang dilakukan dapat disimpulkan bahwa : (1) Terdapat pengaruh brand experience terhadap brand affect (2) Terdapat pengaruh brand image-congruence terhadap brand affect (3) Tidak terdapat pengaruh brand experience terhadap brand trust (4) Terdapat pengaruh brand image-congruence terhadap brand trust (5) Terdapat pengaruh brand affect terhadap brand trust (6) Tidak terdapat pengaruh brand experience terhadap repurchase intention (7) Terdapat pengaruh brand imagecongruence terhadap repurchase intention (8) Terdapat pengaruh brand trust terhadap repurchase intention.

\section{REFERENCES:}

Abdillah, Willy dan Jogiyanto. 2015. Partial Least Square (PLS) - Alteratif Structural Equation Modeling (SEM) Dalam Penelitian Bisnis. Yogyakarta : C.V Andi Offset

Alloza, Angel. 2008. Brand engagement and brand experience at bbva, the transformation of a 150 years old company. Corporate Reputation Review, 11(4), 371- 379. doi:1 0.1057/crr.2008.31

Aslam , Wajeeha, Ham, Marija \& Farhat, Kashif. 2018. Influencing factors of brand perception on consumer repurchase intention: an examination of online apparel shopping. Journal of Contemporary Management Issues. Vol. 23, pp.87-101

Auzolt, Laurent. 2015. Is the congruence between behavioral intention, attitude, norm, and behavioral control normative ?. Studia Psychologica, 57, 2015, 4

Brakus, J.Joskos, Schmitt, Bernd H., \& Zarantello, Lia. 2009. Brand Experience:What Is It? How Is It Measured? Does It Affect Loyalty?. Journal of Marketing, Vol. 73, pp. 52-68

Chaudhuri, A., \& Holbrook, M. B. 2001. The Chain of Effects from Brand Trust and Brand Affect to Brand Performance: The Role of Brand Loyalty. Journal of Marketing, 65(2), 81-93. doi:10.1509/jmkg.65.2.81.18255

Chen-Yu, Jessie, Cho Siwon and Kincade Doris. 2016. Brand perception and brand repurchase intent in online apparel shopping: An examination of brand experience, image congruence, brand affect, and brand trust. Journal of Global fashion Marketing, Vol. 7, no. 1, 30-44

Coulter, Keith S. and Coulter, Robin A. 2002. Determinants of trust in service provider: the moderating role of lenght of relationship. Journal of Service Marketing, vol 16, No. 1, pp. 35-5

Fang, Yu-Hui., Chiu, Chao-Min., and Wang, Eric T.G. 2011. Understanding customers' satisfaction and repurchase intentions. Internet Research, Vol. 21 Issue: 4, pp.479-503

Fianto, Achmad Y.A., Hadiwidjojo, Djumilah., Aisjah, Siti., dan Solimun. 2014. The influence of brand image on purchase behaviour through brand trust. Business Management and Strategy. Vol. 5, No. 2 
Foster, Bob. 2017. Pengaruh pengalaman belanja online produk fashion terhadap kepuasan dan niat beli ulang pelanggan zalora dan berrybenka. Kotigensi Volume 5, No. 1, Hal. 68-76.

Kabadayi, Ebru Tumer and Alan, Alev Kocak. 2012. brand trust and brand affect: their strategic importance on brand loyalty. Journal of Global Strategic Management. Vol. 6, No.1, pp. 89-88

Keegan, Warren J, and Green, Mark C. 2016. Global Marketing. England : Pearson

Kim Hongyoun Hahn and Kim, Jihyun . 2009. The effect of offline brand trust and perceived internet confidence on online shopping intention in the integrated multi-channel context. International Journal of Retail \& Distribution Management, Vol. 37 Issue: 2, pp.126-141

Kumar Mishra, M., Kesharwani, A., and Das, D. 2016. The relationship between risk aversion, brand trust, brand affect and loyalty. Journal of Indian Business Research, 8(2), 78-97

Kusuma, Yohanes Surya. 2014. pengaruh brand experience terhadap brand loyalty melalui brand satisfaction dan brand trust harley davidson di Surabaya. Jurnal Manajemen Pemasaran Petra. Vol.2, No.1, p.p 1-11

Lau, Geok Theng and Lee, Sook Han. 1999. Consumers' trust in a brand and the link to brand loyalty. Journal of Market Focused Management, 4, 341-370

Lin, Miao-Que, and Lee, Bruce C.Y. 2012. The influence of website environment on brand loyalty: brand trust and brand affect as mediators. International Journal of Electronic Business Management, Vol. 10, No. 4 , pp. 308-321

Lovelock, Christopher, and Writz, Jochen. 2011. Service Marketing: People, Technology, Strategy. Pearson.

Neha, Srivastava., Satya, Dash., and Amit, Mookerjee. 2016. Determinants of brand trust in high inherent risk products: The moderating role of education and working status. Marketing Intelligence \& Planning, Vol. 34

Peter, J.P and Olson, J.C. 2009. Consumer Behavior \& Marketing Strategy. New York: McGraw-Hill.

Ramaseshan, B and Stein, Alisha. 2014. Connecting the dots between brand experience and brand loyalty: The mediating role of brand personality and brand relationships. Journal of Brand Management 21, 664683. doi:10.1057/bm.2014.23

Rhee, Jongeun, and Johnson Kim K.P., 2012. Investigating relationships between adolescents' liking for an apparel brand and brand self congruency. Young Consumers: Insight and Ideas for Responsible Marketers, Vol. 13 Iss: 1 , pp.74 - 85

Sekaran, Uma, dan Bougie, Roger. 2016. Research Methods for Business. United Kingdom: John Wiley \& Son Ltd. 7 th edition

Setyorini, Retno and Nugraha, Rizky Prima. 2016. The Effect of Trust Towards Online Repurchase Intention with Perceived Usefulness As An Intervening Variable: A Study on KASKUS Marketplace Customers. The Asian Journal of Technology Management Vol.9 No. 1, pp. 1-7

Sirgy, M Joseph, Lee, Dong-Jin, Johar, J.S, and Tidwell, John. 2008. Effect of self-congruity with sponsorship on brand loyalty. Journal of Business Research. 61, 1091-1097

Suryana, Popo and Dasuki, Eliyandi Sumar. 2013. Analisis Faktor yang Mempengaruhi Keputusan Pembelian dan Implikasinya pada Minat Beli Ulang. Trikonomika. Volume 12, No. 2, Hal. 190-200

Trisnawati, Ella, Suroso Agus, Kumorohadi Untung. 2012. Analisis faktor-faktor kunci dari niat pembelian kembali secara online (study kasus pada konsumen fesh shop). Jurnal Bisnis dan Ekonomi (JBE), Vol. 19, No. 2, Hal. $126-141$

$\mathrm{Wu}$, Goubin and Ye, Shenghong. 2016. The influence of brand image congruence, relationship type and selfconstrual on consumers' purchase intention. Open Journal of Business and Management, 4, 535-548

Zarantello, Lia and Schmitt, Bernd H. 2010. Using the brand experience scale to profi le consumers and predict consumer behavior. Journal of Brand Management. 17, 5 . 